England. Such a study would distinguish further between racial and environmental factors. We now have a panel of patients with MS resident in greater London and elsewhere in England who were born in low-risk areas of the world and who, in spite of their group's low risk, have nevertheless developed the disease. Perhaps these patients have some special genetic or environmental characteristics which have predisposed them to develop MS. It would be valuable to study them fully and to search for possible genetic predisposing factors such as the HLA-3-7 and other antigens and obtain a full history of their environmental background.

Multiple sclerosis is highly prevalent where the standard of hygiene is high and in this respect it resembles adult paralytic poliomyelitis before the introduction of the Salk and Sabin vaccines. ${ }^{8}$ 9 Our findings provide evidence that immunity to MS normally develops in childhood in the low-risk zone and persists when the person moves to an area where MS is highly prevalent. It is suggested that this is because of an early childhood infection by the agent responsible for MS in low-risk zones, probably a virus, which is followed by immunity to the adult form of the disease. The key to the mystery of multiple sclerosis appears to be within our grasp.

This study has been possible only because of the wholehearted co-operation of the staffs of the medical records departments of many hospitals over five years. We would like to thank the neurologists who have allowed us access, with the approval of the medical research committees, to the patients' records. Two neurologists helped with this study: Dr Robert Currier, on sabbatical leave from the University of Mississippi Medical Centre, and Dr Marta Elian of the Midland Centre for Neurosurgery and Neurology. We would also like to thank all the general practitioners who co-operated with the study, the staff of the Office of Population Censuses and Surveys, the family practitioner committees, the National Health Service Register, Southport, and the metropolitan regional hospital boards Several senior medical students, in particular, Mr Derick Wade and Mr Simon Rideout, helped us with the study. Dr F Anderson of the computer department, University College, Dublin, undertook the computer analysis. $\mathrm{Mr}$ Richard Peto, reader in cancer studies, University of Oxford, helped us with statistical advice. The Medico-Social Research Board of Ireland provided facilities for the study.

This study was supported by a research grant from the Multiple Sclerosis Society of Great Britain and Northern Ireland.

\section{References}

${ }^{1}$ McAlpine, D, Lumsden, C E, and Acheson, E D, Multiple Sclerosis-A Reappraisal. London, Churchill Livingstone, 1971.

2 Spillane, J D, Tropical Neurology. London, Oxford University Press, 1973.

${ }^{3}$ Dean, G, British Medical fournal, 1967, 2, 724.

4 Dean, G, and Kurtzke, J F, British Medical fournal, 1971, 3, 725.

5 Leibowitz, U, and Alter, M, Multiple Sclerosis, a Clue to its Cause. Amsterdam, North Holland. 1973.

${ }_{6}^{6}$ Dench, G, New Society, 1975, 32, 135.

${ }^{7}$ Miller, J H, Multiple Sclerosis, $A$ Disease acquired in Childhood. Illinois, Charles C Thomas, 1971.

8 Poskanzer, D C, Shapira, K, and Miller, H, Lancet, 1963, 2, 917.

${ }^{\circ}$ Dean, G, South African Medical Fournal, 1967, 41, 294.

\title{
Treatment of overt meningeal leukaemia in children: results of second MRC meningeal leukaemia trial
}

\author{
M L N WILLOUGHBY
}

British Medical fournal, 1976, 1, 864-867

\section{Summary}

After induction of meningeal remission by a course of intrathecal methotrexate patients were randomly allocated to receive either cranial irradiation or craniospinal irradiation. Patients being treated for their first meningeal relapse were randomised separately from those in their second or subsequent relapse. All eight patients in their first relapse who were given cranial irradiation alone developed further meningeal recurrence (median length of remission 15 weeks) compared with only two out of nine given craniospinal irradiation (median length of remission at least 99 weeks). Four of the nine patients given craniospinal irradiation were alive and without further meningeal relapse two and a half to four years after treatment. Craniospinal irradiation produced no such advantage for patients entering the trial in their second or subsequent meningeal relapse. Toxicity was acceptable, and no patients developed encephalopathy. Craniospinal irradiation after meningeal remission induced by intrathecal methotrexate therefore

Department of Haematology, Royal Hospital for Sick Children, Glasgow G3 8SJ

M L N WILLOUGHBY, MD, MRCPATH, consultant heamatologist and member of MRC Working Party on Childhood Leukaemia provides a practical means of treating children in their first episode of meningeal leukaemia. None of the patients had received previous CNS irradiation and it remains uncertain whether similar results will be obtained in patients developing meningeal leukaemia in spite of cranial irradiation given as CNS prophylaxis early in the disease.

\section{Introduction}

Conventional intrathecal methotrexate treatment alleviates the symptoms of meningeal leukaemia and clears blast cells from the cerebrospinal fluid (CSF) in a high proportion of patients, but the subsequent meningeal remission is short-lived. Without further treatment of the central nervous system (CNS) blast cells reappear in the CSF after a median interval of 16 weeks (range 11-26 weeks). ${ }^{1}$ The value of CNS irradiation given shortly after induction of meningeal remission by intrathecal methotrexate has been investigated in a co-operative randomised trial conducted by the MRC Working Party on Childhood Leukaemia. The trial was designed to determine whether the spinal component of craniospinal radiotherapy contributes to the length of subsequent meningeal remission (fig 1).

\section{Trial}

Criteria for admission - To be admitted into the trial patients had to have acute lymphoblastic leukaemia with a newly-diagnosed meningeal relapse and more than $0.01 \times 10^{\circ}$ mononuclear cells/litre $\left(10 / \mathrm{mm}^{3}\right)$ in the CSF in the absence of an infecting organism, some of the cells 
(Induction)

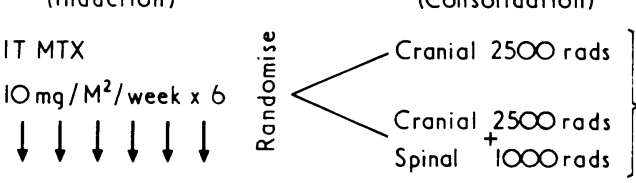

Phase III

(Follow-up)

Diagnostic

lumbar punctures of

8-week intervals
FIG 1 -Plan of trial. IT = luntrathercal. $\quad$ MTX $=$ Methotrexate.

being identifiable as blast cells on a stained concentrate or cytospin film. CSF protein and sugar concentrations were recorded, and informed consent for completion of the full course of treatment was obtained from the parents or guardian. Patients who had had previous prophylactic intrathecal methotrexate were not excluded, but those who had had CNS radiotherapy were. Patients with second or subsequent meningeal relapses were included in the trial, but they were randomised separately from those in their first meningeal relapse and constituted a separate group for analysis. Marrow examination was performed on entry to the trial to confirm systemic remission.

Initial findings-Initial clinical findings in the 38 patients admitted to the trial were headache in 26 , vomiting in 29 , recent weight gain of over $1 \mathrm{~kg}$ a month in 10 , papilloedema in 24 , and retinal vein engorgement (without papilloedema) in 4. Other CNS symptoms were present in 16 children; these included lethargy (2 cases), ocular symptoms (4), pain (4), irritability (1), somnolence (1), ataxia (1), and fits (1). Neurological abnormalities included ataxia in 2 patients, intention tremor in 1 , convulsion in 1 , and Kernig's sign in 1 . No significant differences in symptoms between patients in their first relapse and those in subsequent relapses were apparent. The results of CSF examination are shown in table I.

\section{TREATMENT}

Phase 1 (induction)-Initial treatment of the meningeal leukaemia consisted of at least six doses of intrathecal methotrexate $\left(10 \mathrm{mg} / \mathrm{m}^{2}\right)$ given each week until the CSF showed a nucleated cell count of less than $0.01 \times 10^{9} / 1\left(10 / \mathrm{mm}^{3}\right)$ on two successive lumbar punctures. Those failing to achieve remission or with a residual neurological deficit were removed from the trial. Methotrexate for intrathecal injection was prepared immediately before use by dissolving the contents of a $50-\mathrm{mg}$ phial in $20 \mathrm{ml}$ sterile water. This was done to reduce the concentration of preservatives (preservative-free solution of methotrexate for intrathecal use was not generally available at the beginning of this trial).

Phase 2 (consolidation)-Patients in meningeal remission were then randomised to receive either cranial irradiation alone (2500 rads supervoltage in 12 fractions given over two and a half weeks) or cranial irradiation plus spinal irradiation (1000 rads supervoltage or a biologically equivalent orthovoltage dose in four or five fractions over four to six days). The cranial dose was limited to 2000 rads for children aged 1-2 years and to 1500 rads for those under 1 year (in fact, all patients were aged 2 years or more and were given 2500 rads). Patients remained on their scheduled systemic chemotherapy throughout the trial, but during the five days of spinal radiotherapy this took precedence over systemic therapy.*

Phase 3 (follow-up)-Follow-up to determine the length of meningeal remission consisted of diagnostic lumbar punctures, without further methotrexate, every eight weeks after completion of the CNS irradiation or when clinically indicated. The criterion of meningeal relapse in life was a nucleated cell count of over $0.01 \times 10^{9} / 1$ with identifiable blast cells on a concentrate or cytospin film. In most patients the change in cell count preceded the development of CNS symptoms, which were present in only five patients at the time of recurrence. In patients dying of systemic disease histological evidence of leukaemic infiltration of meninges was sought. When no necropsy was performed and there were no clinical suspicions of CNS recurrence the meningeal remission was taken as extending only up to the time of the last recorded lumbar puncture and the patient was classified as dying in meningeal remission. One patient who developed an undoubted hypothalamic syndrome, but who had no identifiable blast cells in the CSF, was classified as having CNS recurrence and withdrawn from follow-up. His subsequent clinical response to intrathecal methotrexate supported this classification.

\section{Results}

In the 38 patients who entered the trial intrathecal methotrexate produced clinical and CSF remission in 35 patients (including three who were later withdrawn by their parents and three who died of systemic disease before phase 3 ). The nucleated CSF cell count usually fell to below $0.01 \times 10^{9} / 1$ by the third or fourth dose but four patients needed five or six doses to achieve this level. The remaining three patients were withdrawn in phase 1 : one because he developed headache and vomiting after the third dose of methotrexate; one because he failed to respond to methotrexate (raised CSF cell counts and protein concentrations persisted after seven doses); and one because he received intrathecal cytarabine instead of methotrexate. Thus methotrexate induced meningeal remission in $95 \%$ of patients

*Guidelines for intercalating the course of intrathecal methotrexate with various systemic chemotherapy schedules are given in the trial protocol, obtainable on request from the MRC Leukaemia Trials Office, Royal Marsden Hospital, Fulham Road, London SW3.

TABLE I-CSF findings on entry to trial. Results are median values (and ranges)

\begin{tabular}{|c|c|c|c|c|c|c|c|}
\hline & $\underset{\text { patients }}{\text { No of }}$ & $\begin{array}{l}\text { Cell count } \\
\left(\times 10^{9} / 1\right)\end{array}$ & $\begin{array}{l}\text { No with } \\
\text { abnormal } \\
\text { cell count }\end{array}$ & $\begin{array}{c}\text { Protein } \\
(\mathrm{g} / \mathrm{l})\end{array}$ & $\begin{array}{c}\text { No with } \\
\text { abnormal } \\
\text { protein levels }\end{array}$ & $\underset{(\mathrm{mmol} / \mathrm{l})}{\text { Sugar }}$ & $\begin{array}{l}\text { No with } \\
\text { abnormal } \\
\text { sugar levels }\end{array}$ \\
\hline $\begin{array}{l}\text { Normal* } \\
\text { Patients in 1st relapse } \\
\text { Patients in subsequent relapses }\end{array}$ & $\begin{array}{l}22 \\
16\end{array}$ & $\begin{array}{l}<<0.01 \\
0.7(0.006-2 \cdot 62) \\
0.373(0.013-5 \cdot 7)\end{array}$ & ${ }_{16}^{21 \dagger}$ & $\begin{array}{l}<0.4 \\
0 \cdot 2(0 \cdot 1-1 \cdot 7) \\
0 \cdot 3(0 \cdot 1-1 \cdot 4)\end{array}$ & $\begin{array}{l}7 \\
3\end{array}$ & $\begin{array}{l}>2 \cdot 8 \\
2 \cdot 5(1 \cdot 2-4 \cdot 0) \\
2 \cdot 7(0 \cdot 8-3 \cdot 6)\end{array}$ & $\begin{array}{r}13 \\
9\end{array}$ \\
\hline
\end{tabular}

*According to criteria of Sullivan et al. ${ }^{13}$

Only one patient had an initial cell count less than $0.01 \times 10^{\%} / 1$. The cells were morphologically blast cells and he later had a further meningeal relapse.

Conversion: SI to traditional units-Cell count: $1 \times 10^{\circ} / 1=1000 / \mathrm{mm}^{3}$. Sugar: $1 \mathrm{mmol} / 1 \approx 18 \mathrm{mg} / 100 \mathrm{ml}$.

TABLE II-Summary of results of treatment in 38 children with acute lymphoblastic leukaemia

\begin{tabular}{|c|c|c|}
\hline $\begin{array}{l}\text { No entering trial } \\
\text { No withdrawn }\end{array}$ & $\begin{array}{r}38 \\
9\end{array}$ & $\left.\begin{array}{l}3 \text { because parental consent was withdrawn } \\
3 \text { died from systemic disease before phase III } \\
1 \text { failed to respond to IT MTX } \\
1 \text { withdrawn because of MTX toxicity } \\
1 \text { given IT cytarabine instead of MTX }\end{array}\right\} 6$ achieved meningeal remission on IT MTX \\
\hline $\begin{array}{l}\text { No evaluable: } \\
\text { No in 1st meningeal relapse: } \\
\text { No given craniospinal irradiation }\end{array}$ & ${ }^{29}{ }_{9}$ & $\begin{array}{l}2 \text { developed meningeal relapse } \\
3 \text { died of systemic disease without meningeal relapse } \\
4 \text { alive without meningeal relapse }\end{array}$ \\
\hline No given cranial irradiation & 8 & 8 developed meningeal relapse, and 1 of them died ( 17 months after meningeal relapse) \\
\hline $\begin{array}{l}\text { No in subsequent meningeal relapse: } \\
\text { No given craniospinal irradiation }\end{array}$ & ${ }^{12} 6$ & $\begin{array}{l}5 \text { developed meningeal relapse, and } 4 \text { of them died } \\
\text { I died in meningeal remission }\end{array}$ \\
\hline No given cranial irradiation & 6 & 6 developed meningeal relapse, and 5 of them died of systemic diesease \\
\hline
\end{tabular}


(35 out of 37 receiving methotrexate). Simultaneous marrow relapse was present in only one patient entering the trial, although it developed in another three patients before they reached phase 3.

Of the 29 patients who were evaluable, 17 were in their first meningeal relapse and 12 were in their second or subsequent relapse (table II).

First meningeal relapse-Among patients being treated for their first episode of meningeal leukaemia only two out of nine receiving craniospinal irradiation had a subsequent recurrence compared with eight out of eight receiving only cranial irradiation $\left(\chi^{2}=7.4 ; P<0.01\right.$, using $2 \times 2$ table and Yates's correction for small numbers). Four of the craniospinal group were alive without meningeal recurrence 135 to 200 weeks after completion of their CNS treatment (fig 2); they included two patients (free of recurrence at 66 and 114 weeks) who had responded slowly to methotrexate treatment. Three patients in this group died of systemic disease without clinical features of CNS leukaemia and with normal CSF at their last lumbar puncture (shown by arrows in fig 2). The median length of meningeal remission was at least 99 weeks among the nine patients given craniospinal irradiation compared with 15 weeks among the eight patients given only cranial irradiation. There were no significant differences between the patients allocated to craniospinal or cranial irradiation in age, CSF blast cell count at entry, white blood count at diagnosis, interval between diagnosis and development of meningeal leukaemia, or interval between last dose of intrathecal methotrexate (phase 1) and the start of radiotherapy (phase 2).

Subsequent meningeal relapse-No comparable degree of advantage for craniospinal irradiation over cranial irradiation was found in the patients treated for their second or subsequent meningeal relapse (fig 3). In the craniospinal group five of the six patients relapsed, and four of these, together with the patient who remained in remission, died of systemic disease. All six of the patients who received cranial irradiation relapsed and five of them died of systemic disease. The

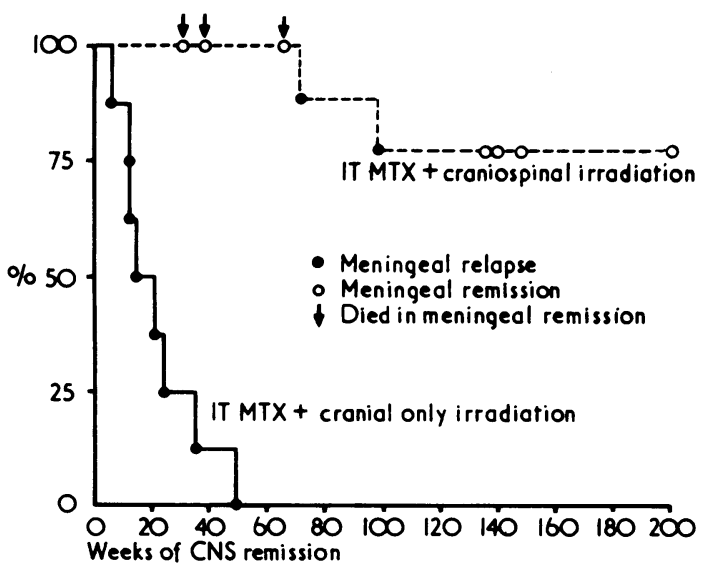

FIG 2-Length of CNS remission in children treated for their first episode of meningeal leuksemia: cranial $v$ craniospinal radiotherapy after intrathecal methotrexate (IT MTX).

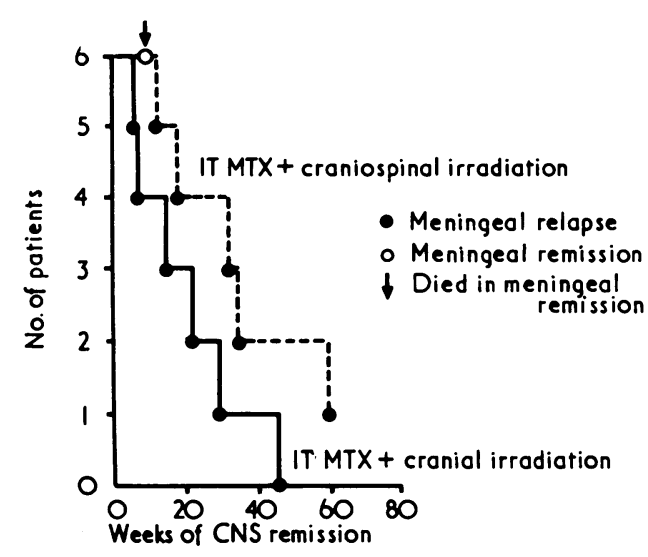

FIG 3-Length of CNS remission in children treated for their second or subsequent meningeal relapse: cranial $v$ craniospinal radiotherapy after intrathecal methotrexate (IT MTX). median length of remission in the cranial group (14 weeks) was similar to that among similarly treated patients in their first relapse.

Considering all 29 patients together, irrespective of how many relapses they had had at entry to the trial, significantly fewer patients relapsed after craniospinal irradiation (7 out of 15) than after cranial irradiation (14 out of 14$)\left(\chi^{2}=7 \cdot 7 ; P<0.01\right.$, using Yates's correction).

Toxicity in phase 1 was limited to vomiting and headache in three patients, buccal ulceration in five, and transient neutropenia $(0.39$ $\left.\times 10^{9} / 1\left(390 / \mathrm{mm}^{3}\right)\right)$ in one, these being attributed to the intrathecal methotrexate. In only one patient was the headache and vomiting sufficient for them to be withdrawn from the trial. Toxicity in phase 2 consisted solely of temporary alopecia, which was invariable. Postradiation somnolence was not recognised.

\section{Discussion}

Attempts to improve the duration of meningeal remission have included administering five or six additional doses of intrathecal methotrexate after the CSF has become normal'; systemic intravenous carmustine (BCNU) or maintenance intrathecal methotrexate given every eight weeks during meningeal remis$\operatorname{sion}^{13}$; combination intrathecal chemotherapy with methotrexate, cytarabine (cytosine arabinoside), and hydrocortisone ${ }^{4}$ cranial irradiation (2400 rads) and intrathecal methotrexate ${ }^{5}$; and craniospinal irradiation (2000-2400 rads) without methotrexate. ${ }^{3}$ " Craniospinal irradiation used as "consolidation" treatment after methotrexate-induced meningeal remission has not been used before.

If total eradication of overt meningeal leukaemia is the goal then intrathecal drugs alone may be doomed to failure. One reason for this may be the occurrence of perivascular "cuffing" by leukaemic cells deep within the substance of the brain and spinal cord in association with the more superficial arachnoidal infiltration of meningeal leukaemia. ${ }^{7}$ Although these deeper cells lie in an extension of the subarachnoid space, some will be relatively inaccessible to intrathecal drugs and might act as feeder cells for subsequent reseeding of the CSF. Another reason for the failure of intrathecal cycle-active drugs such as methotrexate and cytarabine to eradicate meningeal leukaemia may be the slow proliferative rate of the leukaemic cells, with less than $2 \%$ in the $S$ phase and a mitotic index of under $0.1 \% .^{8}$

Craniospinal irradiation produced a much longer meningeal remission than cranial irradiation alone, both types of treatment being administered when the CSF had been cleared of blast cells by a course of intrathecal methotrexate. This finding implies that $(a)$ there is residual disease in the spinal area not reached by intrathecal methotrexate but susceptible to spinal irradiation (1000 rads), such as the perivascular cuffing described above or perhaps dural extension of the meningeal infiltration, or (b) simultaneous attack on both cranial and spinal meninges is necessary for maximum eradication of the leukaemic infiltrate because of the free communication between cranial and spinal CSF. Reseeding of the spinal CSF could take place during the interval between the last dose of methotrexate and the beginning of cranial irradiation.

The absence of comparable benefit from craniospinal irradiation in second or subsequent meningeal relapses suggests that the more extensive infiltration likely to be present in these patients is no longer susceptible to the dose of radiotherapy used. This might be explained by the greater radiosensitivity of small tumour cell deposits compared with larger masses. ${ }^{\circ} \mathrm{A}$ higher dose of spinal radiation might be more effective in such cases, but the greater resulting myelodepression and immunosuppression would tend to compromise subsequent systemic chemotherapy.

Cranial irradiation was followed by short meningeal remissions in all patients irrespective of how many relapses they had had. The median duration in these patients (98-105 days) is identical to the median length of remission obtained after methotrexate induction alone (106 days). ${ }^{3}$ It is also close to the median duration of 125 days reported by Duttera et al after intrathecal methotrexate and cranial irradiation. ${ }^{5}$ They concluded that " 2400 rads to the cranial vault did not improve the therapeutic 
effect achieved with intrathecal methotrexate alone." Our observations agree with this statement, confirming the inadequacy of cranial irradiation alone and emphasising the efficacy of the spinal component of craniospinal radiation.

The length of meningeal remission after craniospinal irradiation, reaching from one to over three years in five patients, establishes this schedule as a practical means of treating first episodes of overt meningeal leukaemia. The median duration of 99 weeks unmaintained meningeal remission was a conservative estimate. This would have been the figure if all three of the children dying without meningeal relapse had lived to develop it before this point. Although the numbers of patients were small this remission was longer than the longest previously reported median remission of 67 weeks, ${ }^{1} 34$ weeks, ${ }^{3}$ and over 33 weeks ${ }^{5}$ (obtained with maintenance intrathecal methotrexate given every eight weeks during remission). Our results were obtained without the added imposition of repeated intrathecal injections and their associated symptomatic side effects during remission. Craniospinal irradiation (2400 rads) without prior clearing of the CSF blast cells by methotrexate produced long-term remissions extending for eight to 43 months in 13 out of 32 children, ${ }^{8}$ but about a third of these patients showed meningeal relapse after a median duration of nine months ( 39 weeks), which suggests that slightly better results may be obtained when craniospinal irradiation is given after remission induced with intrathecal methotrexate, even though the spinal dose of irradiation is lower (1000 rads in the present study). The lower spinal dose was used in an effort to avoid undue marrow and immunosuppression in children who had already been on systemic antileukaemic chemotherapy for one or more years and who were likely to remain on such treatment for a similar period. The subsequent survival of five patients for one to more than three years after completion of the craniospinal radiotherapy indicates that this dose of spinal radiotherapy did not unduly compromise subsequent systemic chemotherapy.

Serious encephalopathy ${ }^{10-12}$ was not encountered in this trial.
There might, however, be a hazard of radiation-induced brain damage in patients given a second course of CNS irradiation who have already had cranial irradiation as a component of CNS prophylaxis early in their disease. This commonly applies to patients currently presenting with their first episode of meningeal leukaemia. Several such patients are now receiving a second course of cranial plus spinal irradiation, so far without a report of serious complication. This question, as well as that of the efficacy of the treatment in patients who have already had CNS prophylaxis, will therefore be answered in time.

Finally, the findings of the present trial may be relevant to the design of improved initial "prophylactic" treatment of the CNS, since this is similarly directed at eliminating small numbers of leukaemic cells in the CNS. For instance, the addition of 1000 rads to the spine might give a lower rate of meningeal relapse than intrathecal methotrexate and cranial irradiation alone.

This trial was conducted by the Medical Research Council Working Party on Childhood Leukaemia.

\author{
References \\ ${ }^{1}$ Sullivan, M P, et al, Blood, 1971, 38, 680. \\ 2 Selawry, O S, and Odom, S, Proceedings of the American Association for \\ Cancer Research, 1968, 9, 62. \\ 3 Sullivan, M P, et al, Cancer, 1975, 35, 1066. \\ 4 Sullivan, M P, et al, Proceedings of the American Association for Cancer \\ Research, 1971, 12, 45. \\ ${ }^{5}$ Duttera, M J, et al, Lancet, 1973, 2, 703. \\ ${ }^{6}$ Hustu, H O, et al, Cancer, 1973, 32, 585. \\ ${ }^{7}$ Price, R A, and Johnson, W W, Cancer, 1973, 31, 520. \\ ${ }^{8}$ Huei-Mei Kuo, A, et al, Cancer, 1975, 36, 232. \\ - Cohen, L, in Biological Basis of Radiation Therapy, ed E E Schwartz. \\ Philadelphia, Lippincott, 1966. \\ ${ }^{10}$ Kay, H E M, et al, Archives of Disease in Childhood, 1972, 47, 344. \\ ${ }^{11}$ Rubinstein, L J, et al, Cancer, 1975, 35, 291. \\ 12 Price, R A, and Jamieson, P A, Cancer, 1975, 35, 306. \\ 13 Sullivan, M P, et al, Blood, 1969, 34, 301.
}

\title{
Bronchial reactivity to histamine before and after sodium cromoglycate in bronchial asthma
}

\author{
BANN KANG， ROBERT G TOWNLEY，C K LEE， BETTY MILLER KOLOTKIN
}

British Medical fournal, 1976, 1, 867-870

\begin{abstract}
Summary
Out of 19 patients with extrinsic bronchial asthma challenged with $123 \mu$ g histamine acid phosphate by intravenous infusion only 13 responded with a fall in FEV $_{1}$ of over $10 \%$ (mean $16 \%$ ). Seventeen of these patients were given histamine $2 \mathrm{mg} / \mathrm{ml}$ by aerosol, and all responded with a mean decrease in $F_{E V}$ of $37.8 \%$. When challenged with allergen extract by aerosol the mean decrease in $\mathrm{FEV}_{1}$ was $37.5 \%$. After $40 \mathrm{mg}$ sodium cromoglycate 15 of the 17 patients showed significant protection
\end{abstract}

\footnotetext{
Allergic Disease Centre and Department of Medicine, Creighton University School of Medicine, Omaha, Nebraska 68178

BANN KANG, MD, fellow in allergy and clinical immunology

ROBERT G TOWNLEY, MD, professor of medicine and microbiology $C \mathrm{~K}$ LEE, MD, fellow in allergy and clinical immunology

BETTY MILLER KOLOTKIN, MD, fellow in allergy and clinical immunology
}

against allergen challenge with a mean decrease in $\mathrm{FEV}_{1}$ of only $23 \cdot 6 \%$.

Inhalation of $40 \mathrm{mg}$ sodium cromoglycate, however, failed to protect against histamine given by either the intravenous or aerosol route. Histamine given intravenously to asthmatic patients produces less of a bronchial response than when given by aerosol, even though the intravenous route produces many more systemic symptoms, such as flushing and throbbing headache. The protection of sodium cromoglycate against an allergen inhalation challenge is not due to histamine antagonism.

\section{Introduction}

Sodium cromoglycate is an important and useful prophylactic drug in asthma. It inhibits immediate-type hypersensitivity reactions to antigen both in vitro and in vivo. ${ }^{12}$ In man the previous inhalation of sodium cromoglycate suppresses the immediate reaginic bronchial reaction to inhalation challenge with allergen. It also prevents the late (four to six hours) increase in airway obstruction in cases in which immediate and late reactions occur. ${ }^{2-5}$ 